\title{
What future for the policy sciences?
}

\author{
ROGER A. PIELKE JR.
}

CIRES Center for Science and Technology Policy Research, University of Colorado, Boulder, 1333

Grandview Avenue, UCB 488, Boulder, CO 80309-0488, U.S.A.; E-mail: pielke@colorado.edu

\begin{abstract}
The term "policy sciences" refers both to a distinctive tradition within the policy movement and to the broader policy movement itself. While the generic use of this term is sure to persist, the community of policy scientists trained in the tradition founded by Harold Lasswell and Myres S. McDougal faces challenges to its sustainability as a distinctive tradition of the policy movement. To motivate open discussion and debate, this essay follows the logic of a problem-oriented analysis, and also includes personal reflections and anecdote, with the following objectives: It suggests that the policy sciences tradition faces challenges to its sustainability because of the simple arithmetic of generational turnover in university faculty. It explores six factors internal and external to the policy sciences community militating against sustainability. The essay then critiques three different roles the policy scientist might play in contemporary academia, and concludes with a discussion of alternatives that might enhance the sustainability of the policy sciences tradition, should sustainability indeed be a desired outcome.
\end{abstract}

\section{Introduction}

In the coming years, the policy sciences face a milestone. To be sure, that day may be a decade or more in the future, but inevitably it will come. I refer to that future date when the last student trained by the tradition's founders, Harold Lasswell and Myres S. McDougal, calls it a career and passes to subsequent generations of scholars the responsibility for sustaining the policy sciences as a distinct tradition within the policy movement. But who will be there to accept this responsibility? And, more fundamentally, if sustainability is desired (itself an open question), how might the policy sciences overcome those factors that militate against sustainability? These questions are worth asking today as our actions taken in the short term will affect the long-term sustainability of the policy sciences. Even if uncomfortable, this is a debate worth engaging in public and as a community.

My analysis assumes the reader is familiar with the distinctive problem-oriented, contextual, and multi-method perspective of the policy sciences tradition, its commitment to a realization of human dignity, and how the policy sciences framework differs from other traditions within the policy movement (for an overview, see Clark, 2002). This essay originated as a discussion paper in 2001 as a response to questions raised by graduate students studying the policy sciences at the University of Colorado. As members of the largest and one of only two graduate programs (the other one is Yale) offering comprehensive graduate training in the policy sciences, our students often ask about the future of the policy sciences tradition.

Writings on the sustainability of the distinctive policy sciences tradition include the highly critical (e.g., Falk, 1995), sincerely concerned (e.g., Ascher and Brunner, 1995), and simply dismissive (e.g., Fischer 2003). This essay, which might be considered an extended editorial, takes the form of a problem-oriented analysis, but 
it also includes personal reflections and anecdote. Although the paper raises some uncomfortable issues, my purpose is neither to criticize the policy sciences tradition, of which I am part, nor members of its community. It does, however, raise a blunt and perhaps uncomfortable question: What future do we wish for the policy sciences?

\section{What is the problem?}

Questioning the future of the policy sciences tradition is not a new endeavor. For example, in their justification of a professional society of policy scientists, Ascher and Brunner (1995) argue that the distinctive tradition of the policy sciences is "losing ground;" it has been left in the shadow of more traditional disciplinary approaches to policy research. More generally, Schön and Rein (1994: p. xvi) claim, "the policy analytic movement begun by Harold Lasswell in the early 1950s has largely failed" because of the perception and reality that policy research has contributed little to improved decision making (cf., Fischer, 2003). Whether or not such claims are substantively correct or remain current, we policy scientists believe (and have ample evidence, e.g., Wallace, 2003) that in our tradition lies considerable potential for improving intelligence in decision making. To the extent that addressing challenges to sustainability facing the policy sciences as a distinct intellectual tradition also helps to address the broader challenges faced by the policy movement, policy scientists have a responsibility to sustain their distinctive tradition.

Sustainability is an issue worth raising because of the simple arithmetic of faculty turnover. Academic schools of thought sustain themselves through the training of graduate students who fill vacated faculty positions of those who retire from the professorate. Undergraduate education in the policy sciences is of critical importance, no doubt, but alone is not particularly relevant to consideration of the tradition's sustainability, since those with terminal undergraduate degrees rarely find themselves in a position to train future generations of policy scientists. To sustain, the tradition requires graduate students with mastery of the distinctive approach of the policy sciences and an ability to teach that knowledge to subsequent generations of scholars and teachers. The alternative is that the tradition gradually fades into the history as a consequence of inevitable attrition. The number of graduate programs offering comprehensive training in the policy sciences suggests few policy scientists are graduating with Ph.D.s. And more critically, having only two programs offering comprehensive and explicit training in the policy sciences necessarily means limited opportunities for new Ph.D.s to find positions where they can teach the policy sciences as part of a policy sciences curriculum.

My perspective, being trained in and now teaching the policy sciences, is that sustainability is a goal worth pursuing, but this goal should not be taken at face value: it, too, should be examined and questioned. If sustainability is indeed worth pursuing, then no matter what else the policy sciences community achieves, its longterm success means that it must also continuously replenish its ranks to create a robust, resilient, and diverse community of scholars who share the tradition's values and aspirations. However, there are at least six factors that militate against the tradition's sustainability. 


\section{External factors militating against sustainability}

Three characteristics of the broader policy movement not generally shared by the policy sciences community (and hence, external) create a bias against the sustainability of the distinctive tradition of the policy sciences. These are (a) the revered role of prediction, (b) a particular axiology of science, and (c) the increasing politicization of science. The following sections consider each in turn.

\section{The revered role of prediction in the policy movement}

Prediction occupies two roles in modern science and society. First, for scientists (natural or social) predictive capabilities purport to validate theory, demonstrating the correctness of the context-independent laws or relationships that underpin theory (Sarewitz et al., 2000; Flyvbjerg, 2001). As well, prediction also occupies a revered role within the broader policy movement, even as it is de-emphasized by the policy sciences tradition (cf. Brunner, 1991). Fischer (1998) describes the role of prediction in the policy movement:

The goal is to generate a body of empirical generalizations capable of explaining behavior across social and historical contexts, whether communities, societies, or cultures, independently of specific times, places, or circumstances. Not only are such propositions essential to social and political explanation, they are seen to make possible effective solutions to societal problems. Such propositions are said to supply the cornerstones of theoretical progress (cf. Hill, 1997).

As deLeon and Steelman (1999: p. 164) observe, "For some years now, the Holy Grail in policy research has been predictive theories."

Fischer (1998) hints at a second role of prediction, to contribute explicitly to decision making. This certainly seems logical since "decision making is forward looking, formulating alternative courses of action extending into the future, and selecting among the alternatives by expectations of how things will turn out" (Lasswell and Kaplan, 1950). The desire of academics to advance predictive knowledge in the context of decision makers looking for insight about the future has led to a seemingly efficient "two birds with one stone" approach to connecting inquiry with action, because the process of research aimed at prediction can be portrayed as a positive step toward solving a policy problem (Sarewitz and Pielke, 1999). Therefore, politicians, natural and social scientists, and policy analysts may see the support of research programs that promise to deliver a predictive capacity in the future as an alternative to recommending or taking politically risky action in the present (cf. Sarewitz et al., 2000).

In practice, such "two-birds-with-one-stone" arguments have carried considerably more weight in the natural sciences than in the social sciences, at least as measured by resources devoted to research. Nonetheless, for many social scientists, emulation of the natural sciences has enabled the pursuit of disciplinary research agendas under the fig leaf of policy relevance. Like their colleagues in the natural sciences, social scientists are influenced by the linear model of science-from basic research motivated 
by curiosity leading to application and ultimately societal benefit. Representative examples include the following:

A growing number of public policy scholars within and outside political science have increasing doubts that the frameworks and concepts which exist for understanding and evaluating public policies are adequate to address serious issues related to the choice of the appropriate institutions and types of policy to foster citizenship and democracy (Ingram and Smith, 1998: p. 1).

The dominant paradigm of the policy process ... has outlived its usefulness and must be replaced, in large part because it is not a causal theory (Sabatier, 1991: p. 147).

Unless we, as a profession [of politcal science], can offer clear theories of how elections, institutions, and policy are connected and deduce predictions from these theories, we shall simply be telling ad hoc stories (Brady, 1993: p. 194).

While such issues might productively occupy the time of social scientists in pursuit of the "Holy Grail" described by deLeon and Steelman (1999), the resolution of such concerns does not appear to be holding back improvement of particular decisions in specific contexts (Brunner, 1991). Because the policy sciences tradition places limited importance on a search for a theoretical Holy Grail, its practitioners can find themselves outside the mainstream of the policy movement.

Axiology of science

A set of normative commitments underlies any culture - political, scientific, or otherwise. Weinberg (1992: 51 ff) suggests four explicitly normative "axiological attitudes," or statements of value, that scientists hold about their profession:

- Pure is better than applied.

- General is better than particular.

- Search is better than codification.

- Paradigm breaking is better than spectroscopy.

In effect, basic research is better than applied research. According to Weinberg, these attitudes are "so deeply a part of the scientist's prejudices as hardly to be recognized as implying" values that underlie modern science. While Weinberg's concern was with the physical sciences in the early 1970s, his perspective remains current and is applicable to all areas of scientific inquiry, including the social sciences (for an update, see Stokes, 1997). Brunner (1991) has made a similar critique focused on the effects of positivism, an orientation that embodies Weinberg's axiology.

Weinberg's axiology of science has a long history. In the latter part of the 1800s, scientists began to resent any "dependence on values extraneous to science" (Daniels, 1967: p. 1699). Many scientists came to believe that abstract thought associated with science represented a higher calling than the development of useful approaches 
associated with technology. According to an 1883 editorial in Science, "the man who discovers nothing himself, but only applies useful principles which others have discovered, stands upon a lower plane than the investigator" (Science, 1883: p. 1).

More than a century later, many social scientists have adopted Weinberg's axiology of science, manifesting itself as "physics envy" in the form of methodological emulation. Cohen (1994: p. 6) explains the consequences:

A social science like economics - which looks somewhat like physics in being quantitative, in finding expression of its principle in mathematical form, and in using the tools of mathematics - tends to rank higher on a scale of both scientists and non-scientists than a social science like sociology or political science which seems less like an 'exact science.'

It is no surprise that many contemporary social scientists tend to be attracted to theory development, modeling, quantitative approaches, and so on (examples from the policy movement are plentiful in Sabatier, 1999; cf. Fischer, 2003).

In a culture that embraces Weinberg's axiology of science, from the perspective of physics-envying colleagues, the policy scientist who emphasizes context, unpredictability, uncertainty, trial-and-error, and normative commitments may easily appear to stand upon a "lower plane." To the extent that Weinberg's axiology of science shapes practices in places like universities, it creates additional disincentives for the sustained teaching and practice of approaches that embrace instead an axiology of science valuing the particular, the applied, and the practical.

\section{The politicization of science}

As politicians and other decision makers have come increasingly to rely on science and in particular prediction as a basis (or substitute, as the case may be) for decision making, the practice of science itself has become increasingly politicized (see Pielke, 2002, for discussion). In many issues of environmental policy, for example, debates about science replace explicit political debate. Under such circumstances, the most straightforward route to contributing knowledge to policy making may be to become an advocate of special interests. Such advocates seek victory in the political fray, where winning means reducing the scope of alternatives, often to a single preferred outcome. If the vast majority of guidance on policy originates from the perspective of special interests, then strong incentives exist to shade or selectively characterize information, which fosters the politicization of science (or of intelligence more broadly).

Ironically, the politicization of science can also motivate demand among decision makers for a perspective more consistent with that of the policy sciences. In decision contexts where intelligence is valued over promotion, effective decision making requires an ability clearly to distinguish policy analysis from political advocacy. From the perspective of the policy sciences, one important purpose of analysis is to increase the range of alternatives available to decision makers by clearly associating the existing state of knowledge with valued outcomes via a range of choices. By contrast, the goal of advocacy is to decrease the range of alternatives (often to a single preferred option) available to policy makers. My sense is that most contemporary academics 
(including those that comprise the bulk of the policy movement outside of the policy sciences) seeking to connect their expertise with decision making favor participation in advocacy over analysis, in promotion over intelligence. If this is at all close to correct, it then creates additional difficulties for the policy scientist seeking to improve the intelligence on which decisions are based.

\section{Internal factors militating against sustainability}

The assertions raised in this section are largely anecdotal and personal based on my professional, academic, and teaching experiences during the past 10 years. The three sections follow the framework presented by Ascher and Brunner (1995) to describe conditioning factors shaping challenges facing the policy sciences: faculty and degrees, course materials and pedagogy, and a distinctive identity.

\section{Faculty and degrees}

A search of the Internet performed in early 2004 strongly suggests that there are no academic programs offering graduate degrees in the policy sciences (in stark contrast to programs in policy studies, policy analysis, public affairs, socio-economics, etc.), with the exception of the University of Maryland-Baltimore County (2002); however, the UMBC program does not appear to base its curriculum on the distinctive tradition of the policy sciences, but instead on other traditions within the policy movement.

Logically, lack of degree programs implies no demand for formally trained policy scientists to serve in faculty positions. Those few who received doctoral degrees based on policy sciences training find employment in academia in almost every instance in non-policy sciences departments. Consequently, no "pipeline" exists to produce new policy sciences doctorates to fill the shoes of those who retire. For example, as we at the University of Colorado look to expand through new policy faculty our graduate programs that focus on environmental studies and science and technology policy, I have concerns about where we will find applicants with policy sciences expertise. Were the policy sciences tradition to be studied by ecologists, they might easily find it to be a "population in crisis" and "below its carrying capacity."

\section{Course materials and pedagogy}

A 2002 effort led by Richard Wallace to collect and post on the WWW syllabi of courses taught in the policy sciences tradition resulted in 16 submissions from members of the Society for the Policy Sciences, a large number of which originated from the University of Colorado policy sciences programs. ${ }^{1}$ The lack of dedicated degree programs contributes to the dilution of policy sciences expertise across academia. Consequently, neither students nor faculty will have the necessary exposure to the policy sciences to do much more than contribute to "partial approaches." Brunner (1997) documents challenges involved with teaching the policy sciences and argues that partial approaches to the policy sciences found in many of the dominant traditions of the policy movement are inadequate because "we are what we teach." 
My own teaching experiences using the works of Lasswell, in particular, bears out in a general fashion one of Falk's (1995) specific critiques of $A$ Jurisprudence for a Free Society (Lasswell and McDougal, 1992) - specifically, that the writing is "too idiosyncratic and demanding to engage readers, and requires excessive effort to achieve the practical purpose of promoting a useful and ethically attractive approach ..." (p. 1997). In response, Brunner (1996: p. 64) suggests that policy scientists might produce articles "for the education of a new generation in touch with enduring ideas as well as the recent literature." With such articles Brunner recommends "maintaining the integrity of the core, improving and periphery through use, and making them more accessible." There are some recent positive developments, such as the work of Clark (2002) and the case studies discussed by Wallace (2003), but more materials remain needed across the spectrum of topics such as the maximization postulate, decision process, social process, and problem orientation.

\section{Lack of a distinctive identity}

The policy sciences lack a distinctive identity within the policy movement, in spite of a journal, a professional society, and a website (www.policysciences.org). Consider the following example of the deleterious effects of the lack of a distinctive identity. Fischer (1998) explains that policy analysis has consistently failed to provide usable knowledge to decision makers because of the neo-positivist orientation of the policy sciences:

Underlying this effort is a fundamental positivist principle mandating a rigorous separation of facts and values, the principle of the "fact-value dichotomy" .... In the policy sciences the attempt to separate facts and values has facilitated a technocratic form of policy analysis that emphasizes the efficiency and effectiveness of means to achieve politically established goals ( $p$. 130).

Fisher associates a neo-positivist orientation with the term "policy sciences," in stark contrast to the post-positivist orientation held by most self-described policy scientists.

Furthermore, Fischer's analysis is substantively consistent with the diagnosis made by Brunner (1991) but for the important exception that Brunner sees the "policy sciences" as the solution to this failing of policy analysis, not the source of the problem. Clearly Brunner (1991) and Fischer (1998) mean different things when each invokes the term "policy sciences," even though each highlights the importance of the analyst's observational standpoint, values, context, and process. A lack of a distinctive identity for the policy sciences tradition allows it to come under attack by one who espouses a shared perspective.

\section{Who is the policy scientist?}

Clarification of goals is a critical step towards effective progress with respect to the future of the policy sciences tradition. My perspective is that the policy scientist is 
neither a social scientist as defined by conventional standards nor a political advocate for special interests but instead, an analyst whose skills of integration of knowledge and contextual mapping can contribute intelligence to decision makers enhancing the likelihood of attaining desired outcomes.

Social scientist?

My perspective is that the policy sciences are distinct from the social sciences. Today many social scientists remain in thrall of the natural sciences, or at least their notion of the natural sciences (Ross, 1991; Cohen, 1994). Along with emulation of the methods of the natural sciences comes a focus on predictive theory and a commitment to Weinberg's axiology of science. As argued earlier, pursuit of a theoretical Holy Grail introduces pathologies to efforts to make the social sciences relevant to decision making and is contrary to the ethos of the policy scientist. So when asked if I, as a policy scientist, am a social scientist, I typically reply "no." Policy sciences are consistent with expertise in the social sciences, but just as well, natural scientists, engineers, and other experts can also become policy scientists. Of course, one could expand the definition of "social science" to include the policy sciences, in a manner similar to what Flyvbjerg (2001) has sought to do using the term "phronetic social science" and Scott (1998) through the term "metis" (cf. Fischer, 1998), but it is worth distinguishing policy science from social science for at least two reasons.

First, distinguishing policy science from social science allows space for advancing knowledge for knowledge's sake, i.e., for basic research in both the social sciences. Maintaining a distinction between research focused on traditional social science disciplines and problem-oriented research could help move beyond the "two birds with one stone" justification for science in policy.

Second, the policy sciences are in many ways a-disciplinary or trans-disciplinary in that its distinctive orientation is consistent with, in principle, any methods or any knowledge in any discipline, depending on the problem at hand. Labeling the policy sciences as just another social science would misleadingly imply a parallelism with social science disciplines. Further, distinguishing the policy sciences as a separate endeavor from the social sciences would serve to avoid meaningless debates as to whether the policy sciences are or are not a science or are a subset of this or that discipline.

\section{Policy advocate?}

The primary contribution of the policy scientist to decision processes is information, or more precisely, intelligence and appraisal. These tasks are distinct from recommending what actions ought to be taken in particular contexts.

The intelligence division is the subgroup making available to the leadership facts and analyses, and clarifying goals and alternatives. It provides expectations, that is, for the consideration of the policy makers of the group. The 
intelligence function may be distinguished from the advisory function, which recommends policy rather than merely presenting policy considerations ... (Lasswell and Kaplan, 1950: p. 193).

Even though the policy scientist has an important role to play in both intelligence and promotion, when seeking to contribute knowledge to decision, it is critical that the policy scientists not conflate intelligence with promotion.

In practice, this means differentiating science results (including social science) from their policy significance. To illustrate the distinction, consider the central conclusion of an international scientific body focused on global climate change: that global average temperature in 2100 will increase anywhere from 1.4 to $5.8^{\circ} \mathrm{C}$. This is a scientific result, and communication to the non-expert of what it means (i.e., the origins of the estimates, how "global average" is defined, the confidence level of the projection, etc.) may require some effort, but communication of what this result means is not the same as assessment of what it signifies for alternative courses of action. The latter is the essence of intelligence. Using the scientific result to justify a particular course of action (only one of many consistent with the state of science), such as the Kyoto Protocol on climate change, is the essence of promotion.

Assessment of the significance of science for action depends upon how trends, conditions and projections are related to valued outcomes, such as human health and environmental sustainability, as well as economic prosperity, etc. The current state of the scientific enterprise (which can be defined to include the policy movement) is such that most scientists associated with academia and scientific societies not linked to advocacy groups, industry, and government typically lack appropriate fora or avoid explicit discussion of the significance of science for policy (Pielke, 2002).

This leads to two typical outcomes: either political advocates are delegated (de facto) the task of interpreting the significance of science for decision makers, or the voices of those who do seek to provide such advice are lost in the political fray. So if one wishes to answer the question "so what does this particular bit of knowledge mean for action?" in almost any scientific context, with very few exceptions decision maker look to political advocates for the answer, in effect creating a world where the significance of science is filtered through existing special interests.

An alternative, or complement, would be for independent analysts to take some responsibility to address the significance for policy of scientific results. This would mean not simply seeking a better way to communicate the results of science to the policy maker, or dropping such results into a method (like cost-benefit analysis), but to develop the capability to place science into policy context, i.e., to address the question: what policy alternatives (conditioned upon various possible valued outcomes) are consistent and inconsistent with scientific results? There is no proposal being made here that the analyst can ever hope to achieve heroic substantive rationality; rather, that there is a distinction to be made between those who only use information to narrow or restrict choice and those who use information in some contexts to increase alternatives available to decision makers. 
Policy analyst?

The policy scientist is a unique type of policy analyst. As a policy analyst the role of the policy scientist is much like that of the cartographer - one who maps the context of particular issues in terms of problems and decisions. The need for the policy scientist with such skills arises because, as Scott (1998: p. 309) notes, "any large social process or event will inevitably be far more complex than the schemata we can devise, prospectively or retrospectively, to map it." The policy scientist has access to a comprehensive framework that allows for the construction of the relevant context associated with problems and decisions (Brunner, 1991). As MacEachren (1995: p. v) notes,

... maps are powerful tools. And have been for centuries, because they allow us to see $a$ world that is too large and too complex to be seen directly ... what we see when looking at a map is not the world, but an abstract representation that we find convenient to use in place of the world. When we build these abstract representations (either concrete ones in map form or cognitive ones prompted by maps) we are not revealing knowledge as much as we are creating it.

Brunner (1991: p. 81) similarly observes, "but in the end, the assessment of a map depends upon action. Only by examining the substantive consequences of the map when used as a basis for action can we understand what has been overlooked or misconstrued."

The components of the policy sciences framework are an orientation - problemfocused, contextual, and methodologically diverse - and a set of tools for the mapping of any decision context (Brunner, 1991). At their most basic, these tools include the maximization postulate, problem orientation, decision process, and social process (see Clark, 2002). Together, the orientation and tools make up the policy sciences framework. It is worth reiterating that the purpose of the policy sciences framework is not the development of predictive theory or generalized knowledge, but specific knowledge related to decisions and problems in context. ${ }^{2}$ This objective is consistent with how Schlager (1999) defines a framework:

Frameworks bound inquiry and direct the attention of the analyst to critical features of the social and physical landscape. Frameworks provide a foundation for inquiry by specifying classes of variables loosely fit together into a coherent structure. Thus, frameworks organize inquiry, but they cannot ... provide explanations for, or prediction of, behavior and outcomes (p. 234). ${ }^{3}$

Policy scientists assert that effective use of the policy sciences framework can lead reliably to more useful knowledge, and can do so more consistently than alternatives.

But for those seeking to advance predictive theory, a framework can be difficult to evaluate. Compare Ostrom (1999):

It is hard to know exactly how to provide an assessment of a framework. The criteria for evaluating theories are relatively well known and accepted. Theories 
are evaluated for their capacity to generate predictions supported by empirical evidence and to provide coherent explanations for observed regularities ( $p .64)$.

Brunner (1991) does not share this view:

Conceptual frameworks may be evaluated on substantive and formal grounds. Substantively, the key question is whether the framework does indeed incorporate the distinctions that have consistently turned out to be the most important and useful across broad ranges of experience. Formally, an adequate framework must be feasible to use within human cognitive constraints, comprehensive enough to cover the principal dimensions of the world outside, and flexible enough to use on any problem (p. 84).

The differing views of Brunner and Ostrom reinforce the distinction made earlier between policy sciences and social sciences.

Critics of the policy sciences framework tend to focus on the decision process (Lasswell, 1956). deLeon and Kaufmanis (2001) identify Sabatier $(1999,1991)$ as a "spokesman" for such critiques. deLeon (1999) writes that policy process frameworks - which he mistakenly labels the "stages heuristic" - have "outlived their usefulness ..." (p. 7). Setting aside Sabatier's misconceptions of the "stages heuristic," this makes about as much sense as claiming that the tools of cartography have become obsolete. As deLeon and Kaufmanis (2001) note, "one can fairly ask if the critics of the policy process framework are attacking the policy process approach as it was posed, rather than what they conceive it to be" (p. 9). Sabatier conflates theoretical "progress" with the development of useful knowledge for decision making, grounded in a perspective steeped in Weinberg's axiology of science. MacEachren (1995: p. 2) provides a convenient analogy:" maps like buildings that are designed primarily for artistic impact are often not functional." A US Geological Survey topographical map is unlikely to provide much insight into the evolution of subsurface geologic strata, but it certainly can be useful as a tool to get from one location to another. The purposes at hand dictate the appropriate role of tools at the analyst's disposal.

From the perspective of the policy scientist, we should expect "partial answers ... input to the ongoing social dialogue about the problems and risks we face and how things may be done differently" (Flyvbjerg, 2001: p. 61). This is evocative of Lasswell (1971: p. 40): "To some extent we are all blind and no doubt will remain so. But there are degrees of impairment, and so far as decision outcomes are concerned, it is the responsibility of the policy scientist to assist in the reduction of impairment." The policy scientist deals with the specific rather than the general, with what is better rather than what is best, and makes the criteria of such evaluations transparent for all to see.

\section{Alternative futures for the policy sciences}

To the extent that the policy sciences tradition offers a set of powerful tools with potential to contribute to improved decision making and the further realization of 
human dignity, threats to the tradition's sustainability are indeed problematic. Under such circumstances, change must occur to enhance the prospects for sustainability. As policy scientists, we can either encourage the external world to become more receptive to the policy sciences, by, for example, seeking (a) to decrease reliance on prediction, (b) to reorder the value system of expertise, or (c) to express a desire for a better connection between science and politics. While such activities are worth pursuing and such changes are indeed possible, they are neither necessary nor sufficient to address the common problem.

Instead, change might come from within the policy sciences community. This would require keeping the policy sciences contemporary and fully engaged with the modern policy movement, while fully recognizing the commitments of intellectual giants of the mid-twentieth century. In short, we must institutionalize to be more like a discipline and a profession. Above all, we must focus on developing and nurturing future generations of policy scientists. The following two sections discuss these recommendations in more detail.

\section{Clarify the unique perspective of the policy sciences}

While many policy scientists are trained in social science departments, the policy sciences are not merely another sect or tribe within the social sciences. Indeed, as scholarship has become more multi-disciplinary and problem-focused in recent years, examples of the "convergence hypothesis" have come from many fields outside of the social sciences (Brunner, 1991; Flyvbjerg, 2001; Scott, 1998). Ascher and Brunner (1995) describe the convergence hypothesis as follows:

Those relative few who are committed to practical improvements tend to converge on the problem-oriented, contextual, and multi-method outlook of the policy sciences, despite initial differences in their specializations. These people are favorably predisposed toward the policy sciences, whether or not they have been exposed to the distinctive tools of the policy sciences.

Tendencies toward convergence are grounds for optimism about the long-term future of the policy sciences. The conceptual and theoretical tools of the policy sciences (or their functional equivalents) will tend to be rediscovered by reflective practitioners as an adaptation to the requirements of practice; and the various partial alternatives may eventually give way to a policy sciences outlook in professional schools that take the requirements of practice seriously.

Such convergence comes at a high opportunity cost, however, if it results in serial, partial rediscoveries of parts of the policy sciences framework, and may serve only to reinforce partial approaches.

One obstacle to further convergence of perspectives on the policy sciences tradition, rather than alternatives, stems from the conflation of Lasswell the policy scientist and Lasswell the social scientist. To be sure, Lasswell, along with McDougal, conceptualized the policy sciences in the years following World War II, and spent much of his latter career on their elaboration (see, Lasswell and Kaplan, 1950; Lerner and 
Lasswell, 1951; Lasswell, 1956, 1971; Lasswell and McDougal, 1992), but he had other roles in his long and eminent career, most notably as a social scientist par excellence. Seidleman (1985: p. 134; Fischer, 1998, makes a similar point) notes the contradictions between Lasswell the social scientist and Lasswell the policy scientist:

... Lasswell bridges two periods in the discipline's [political science] history and in American life. And oddly, Lasswell was something of a maverick in both eras. In Merriam's time, he appeared as the radical advocate of "pure" vs. applied science. Yet after World War II, he returned to the themes of Merriam's reform science at precisely that point when most political scientists were rejecting them. ${ }^{4}$

As Lasswell's closest collaborator, McDougal (1979) noted the distinction between Lasswell the social scientist and Lasswell the policy scientist.

Lasswell's deepest personal commitment was to the creation of a comprehensive theory for inquiry about the individual human being in social process. His goal was to develop a theory which could be made sufficiently precise to facilitate performance of all the different intellectual tasks necessary to the rational clarification and implementation of individual and community policy. To this goal all his particular innovations, including his work in relation to communications research, the psychiatry of decision making and the psychopathology of politics, developmental constructs and futuristics, content analysis, the specification of a theory of values, the collection of trend data and the social planetarium, systems theory, functional as contrasted to conventional analysis, free association as an instrument of thought, and configurative thinking, were but ancillary (pp. 99-100).

This is not to say that Lasswell's work in political science and the social sciences more broadly are irrelevant to the policy sciences (see, for example, Ascher and Hirschfelder-Ascher, 2004). To the contrary, each of the ancillary innovations referred to by McDougal might be considered in context of the theoretical toolbox at the disposal of the policy scientist, or what Brunner (1991) refers to as "central theory of the policy sciences."

The policy sciences tradition, like pragmatism on which it is based, is an "attitude of orientation" (James, [1907] 1963: p. 27). To facilitate the sustainability of the policy sciences as a distinct tradition, its practitioners might consider the option, sure to be controversial, of decoupling the policy sciences tradition of Lasswell and McDougal from the social sciences tradition of Lasswell.

\section{Institutionalize}

It seems to be an uphill struggle (at best) to try to fold the policy sciences into any social science discipline, such as political science, that bases its journals, reward systems, and values on Weinberg's axiology of science. This is not to say that conventional social science cannot be made to matter more (Flyvbjerg, 2001), but simply that 
changing the social sciences is not a prerequisite to improving the contributions of policy research to practical outcomes in particular policy settings.

For the policy scientist, this presents a career paradox. If a decision is made to follow a value hierarchy other than Weinberg's axiology of science, one is likely to face challenges in finding a satisfactory home in most traditional university departments in the social sciences. One is more likely to find a home in a school or program of public policy; however, this too can be difficult as disciplinary tribes often capture such institutions. Most likely, many policy scientists will live a dual life in academia, publicly focusing on the standards and requirements of the discipline while, perhaps surreptitiously or anonymously, contributing problem-oriented, contextual analyses to those outside their discipline. The policy scientist might do this in stages, with the disciplinary activities occurring prior to tenure, and the policy sciences work after, or perhaps choose to follow a more risky approach of trying to do both simultaneously.

A dual life does not suggest a sustainable model for the policy sciences tradition. If the policy sciences evolve in this fashion, policy scientists will find themselves relatively dispersed and sharing little time with those trained in the same tradition, and with few opportunities to train well-rounded, future generations of policy scientists. This situation suggests a need for a policy program focused on training students in the policy sciences tradition. To sustain, in short, the policy sciences must become institutionalized along the lines of a conventional discipline.

\section{Conclusions: A forked road ahead}

Increasingly, opportunities abound for policy scientists in new multi-disciplinary university programs, many of which are focused on aspects of environmental studies. Because such programs are typically comprised of faculty members from many disciplines, few pay much attention to debating whether the policy scholars are from this or that sub-disciplinary tradition that consumes part of the policy movement. To the extent that improving connections of science (social or physical) with the needs of decision making is a criterion for appointment to such departments, the interdisciplinary, problem-oriented training of the policy scientist may provide an advantage.

Ironically perhaps, there appears to be a window of opportunity for policy scientists to accelerate their development in partnership with colleagues from the disciplines of the natural and biological sciences, as well as the humanities. Many natural and biological scientists recognize that their specialized expertise is an insufficient basis for policy and have approached social scientists (admittedly with some trepidation) in hopes of making their science more relevant, but too often physical scientists seeking policy relevance find that social scientists are just as specialized and focused on theory development. The developer of a global circulation model of the atmosphere undoubtedly has little interest in theories of the policy process, but will likely have an interest in understanding how climate science might contribute to policy development. It is here that the policy scientist is uniquely qualified to contribute.

In recent years, organizations historically dominated by natural sciences such as the National Academies of Sciences, the American Geophysical Union, and the American Meteorological Society have increasingly sought to incorporate considerations of policy with their interactions with decision makers. Even if a good deal of the natural 
scientist's motivation is based on a parochial desire to increase funding for science, it does not rule out that science can be more effectively integrated with decision making.

To take advantage of such windows of opportunity, policy scientists seeking to sustain the community's distinctive identity face important choices. Business-as-usual risks fostering unsustainability and the slow but inevitable loss of the policy sciences' distinct identity to the inexorable forces of retirement and generational change. As difficult as it may be, the community must begin to ask: what future for the policy sciences?

\section{Acknowledgements}

Earlier versions of this paper were presented at the October 2002 Policy Sciences Annual Institute held at Yale University, New Haven, CT and at a Policy Sciences Summer Workshop, June 2002 at the University of Colorado, Boulder. It has benefited from the spirited questions and suggestions of the conference participants. Several colleagues provided valuable comments on earlier versions of this paper, in particular, Garry Brewer, Steven Brown, Ron Brunner, Rad Byerly, Sam Fitch, Bob Frodeman, Susan Iott, Bobbie Klein, Rod Muth, Rich Wallace, Andy Willard, and anonymous reviewers. Ron Brunner deserves special acknowledgement: he has shared with me his immense knowledge and wisdom of the policy sciences. It has also benefited from discussions of the policy sciences with the many students in my courses taught at the University of Colorado. Steven Brown expertly and patiently shepherded this paper through several years of reviews, revisions, and reconsiderations. And I would like to thank Ami Nacu-Schmidt for her expert assistance in the preparation of the paper. Of course, all responsibility for the arguments made in this paper lies with me.

\section{Notes}

1. Richard Wallace, personal communication, 16 October 2002.

2. Compare Brunner (1991: pp. 80-81) "The purpose of the policy sciences as 'science' is to realize more of the potential for free choice through the sharing of insight. The purpose is not prediction" (emphasis in original).

3. It is worth noting that Schlager's (1999) definition of a "framework" is somewhat pejorative, as it is placed lower on the hierarchy of approaches to inquiry than theories or models, a canonical example of the axiology of science.

4. On the transformations of American political science, see Ross (1991) and Almond (1990); on the Chicago school in particular, see Karl (1974).

\section{References}

Almond, G. (1990). A Discipline Divided: Schools and Sects in Political Science. Newbury Park, CA: Sage Publications.

Ascher, W. and R. D. Brunner (1995). 'Society for the Policy Sciences,' published online at http://www.colorado.edu/UCB/TheUniversity/Committees/SPS/F/. 
Ascher, W. and B. Hirschfelder-Ascher (2004). 'Linking Lasswell's political psychology and the policy sciences,' Policy Sciences 37: 23-36.

Ayala, F. J. (1996). 'The candle and the darkness,' Science 273: 442.

Brady, D. W. (1993). 'The causes and consequences of divided government: Toward a new theory of American politics?,' American Political Science Review 87: 189-194.

Brunner, R. D. (1991). 'The policy movement as a policy problem,' Policy Sciences 24: 65-98.

Brunner, R. D. (1996). 'A milestone in the policy sciences,' Policy Sciences 29: 45-68.

Brunner, R. D. (1997). 'Teaching the policy sciences: Reflections on a graduate seminar,' Policy Sciences 30: $217-231$.

Clark, T. W. (2002). The Policy Process: A Practical Guide for Natural Resource Professionals. New Haven, CT: Yale University Press.

Cohen, I. B. (1994). Interactions: Some Contacts Between the Natural Sciences and the Social Sciences. Cambridge, MA: The MIT Press.

Daniels, G. H. (1967). 'The pure-science ideal and democratic culture,' Science 156: 1699-1705.

deLeon, P. and K. Kaufmanis (2001). 'Public policy theory: Will it play in Peoria?,' Policy Currents 10(4): 9 .

deLeon, P. and T. Steelman (1999). 'Making public policy programs effective and relevant: The role of the policy sciences,' Journal of Public Policy Analysis and Management 20: 163-171.

Falk, R. A. (1995). 'Casting the spell: The New Haven School of international law,' Yale Law Journal 104: 1991-2008.

Fischer, F. (1998). 'Beyond empiricism: Policy inquiry in post-positivist perspective,' Policy Studies Journal 26: $129-146$

Fischer, F. (2003). Reframing Public Policy. Oxford, UK: Oxford University Press.

Flyvbjerg, B. (2001). Making Social Science Matter: Why Social Inquiry Fails and How It Can Succeed Again. Cambridge, UK: Cambridge University Press.

Hill, K. Q. (1997). 'In search of policy theory,' Policy Currents 7(1): 1-9.

Ingram, H. and S. R. Smith (1998). 'Institutions and policies for democracy: A discussion paper and comments,' Policy Currents 8(1): 1-13.

James, W. ([1907] 1963). Pragmatism and Other Essays. New York: Washington Square Press.

Karl, B. D. (1974). Charles E. Merriam and the Study of Politics. Chicago: University of Chicago Press.

Lasswell, H. D. (1956). The Decision Process: Seven Categories of Functional Analysis. College Park: Bureau of Governmental Research, College of Business and Public Administration, University of Maryland.

Lasswell, H. D. (1971). A Pre-View of Policy Sciences. New York: American Elsevier.

Lasswell, H. D. and A. Kaplan (1950). Power and Society: A Framework for Political Inquiry. New Haven, CT: Yale University Press.

Lasswell, H. D. and M. S. McDougal (1992). Jurisprudence for a Free Society: Studies in Law, Science and Policy, 2 Vols. New Haven, CT: New Haven Press; Dordrecht: Martinus Nijhoff.

Lerner, D. and H. D. Lasswell, eds. (1951). The Policy Sciences: Recent Developments in Scope and Method. Standford, CA: Stanford University Press.

MacEachren, A. M. (1995). How Maps Work: Representation, Visualization, and Design. New York: Guilford Press.

McDougal, M. S. (1979). 'Harold Dwight Lasswell, 1902-1978,' Yale Law Journal 88: 675-679.

Ostrom, E. (1999). 'Institutional rational choice: An assessment of the institutional analysis and development,' in Paul Sabatier, ed., Theories of the Policy Process. Boulder, CO: Westview Press, pp. 35-71.

Pielke, R. A. (2002). 'Policy, politics, and perspective,' Nature 416: 368.

Ross, D. (1991). The Origins of American Social Science. Cambridge, UK: Cambridge University Press.

Sabatier, P. A. (1991). 'Political science and public policy,' Political Science and Politics 24: 144-147.

Sabatier, P. A., ed. (1999). Theories of the Policy Process. Boulder, CO: Westview Press.

Sarewitz, D. and R. A. Pielke, Jr. (1999). 'Prediction in science and policy,' Technology in Society 21: 121-133.

Sarewitz, D., R. A. Pielke, Jr. and R. Byerly (2000). Prediction: Science, Decision Making, and the Future of Nature. Washington, DC: Island Press.

Schlager, E. (1999). 'A comparison of frameworks, theories, and models of policy processes,' in Paul Sabatier, ed., Theories of the Policy Process. Boulder, CO: Westview Press, pp. 233-260.

Schön, D. A. and M. Rein (1994). Frame Reflection. New York: Basic Books. 
Science (1883). 'The Future of American Science', Science 1(1): 1-3.

Scott, J. C. (1998). Seeing Like a State: How Certain Schemes to Improve the Human Condition Have Failed. New Haven, CT: Yale University Press.

Seidelman, R. and E. J. Harpham (1985). Disenchanted Realists: Political Science and the American Crisis, 1884-1984. Albany: State University of New York Press.

Stokes, D. (1998). Pasteur's Quadrant. Washington, DC: The Brookings Institution.

University of Maryland, Baltimore County (2002). 'Policy Sciences Graduate Program,' May 24, http://www.umbc.edu/posi/index.html.

Wallace, R. (2003). 'Review of The Policy Process, by Tim W. Clark, and The Foundations of Natural Resource Policy and Management, eds. Tim W. Clark, Andrew R. Willard, and Christina M. Cromley,' Policy Sciences 36: 343-348.

Weinberg, A. M. (1970). 'The axiology of science: The urgent question of scientific priorities has helped to promote a growing concern with value in science,' American Scientist 58: 612-617.

Weinberg, A. M. (1992). Nuclear Reactions: Science and Trans-science. New York: American Institute of Physics. 